ERC Working Papers in Economics 17/01 January / 2017

\title{
Determinants of Obesity in Turkey: A Quantile Regression Analysis from a Developing Country
}

\author{
Deniz Karaoğlan \\ Department of Economics, Bahçeşehir University, İstanbul, Turkey \\ E-mail: hanifedeniz.karaoglan@ eas.bau.edu.tr \\ Phone: + (90) 2123815621
}

\footnotetext{
Aysit Tansel

Department of Economics, Middle East Technical University, Ankara, Turkey and Institute for the Study of Labor (IZA) Bonn, Germany and

Economic Research Forum (ERF) Cairo, Egypt

E-mail: atansel@ metu.edu.tr

Phone: + (90) 3122102073
} 


\title{
DETERMINANTS OF OBESITY IN TURKEY: A QUANTILE REGRESSION ANALYSIS FROM A DEVELOPING COUNTRY
}

\author{
Deniz Karaoğlan* and Aysit Tansel**
}

January 11, 2017

\begin{abstract}
This study investigates the factors that may influence the obesity in Turkey which is a developing country by implementing Quantile Regression (QR) methodology. The control factors that we consider are education, labor market outcomes, household income, age, gender, region and marital status. The analysis is conducted by using the 2008, 2010 and 2012 waves of the Turkish Health Survey (THS) prepared by the Turkish Statistical Institute (TURKSTAT). The obesity indicator in our study is the individual's Body Mass Index (BMI). QR regression results provide robust evidence that additional years of schooling has negative effect on individual's BMI and this effect significantly raises across different quantiles of BMI. QR results also indicate that males tend to have higher BMI at lower quantiles of BMI, whereas females have higher BMI at the top quantiles. This implies that females have higher tendency to be obese in Turkey. Our findings also imply that the positive effect of age on individual's BMI levels raises across the quantiles at a decreasing rate. In addition, the effect of living in urban or rural areas do not significantly differ at the highest quantile distributions of BMI. Our results also reveal that the negative effect of being single on BMI increases gradually in absolute value across the quantiles of BMI implying that single individuals have less tendency to be obese or overweight compared to the married or widowed/divorced individuals. Moreover, the negative effect of being in labor force on individual's BMI increases across the quantiles of BMI implying that an individual is more likely to be obese if he/she is out of labor force. Finally, the impact of household income on BMI is positive and significant at all quantiles.
\end{abstract}

Keywords: Obesity, adults, BMI, quantile regression, Turkey

JEL Classification codes: I12, I18, C21

*Corresponding Author. Bahcesehir University, Department of Economics. E-mail: hanifedeniz.karaoglan@eas.bau.edu.tr. Tel: +90 2123815621.

**Middle East Technical University, Department of Economics, Ankara, Institute for the Study of Labor (IZA), Bonn, Germany, Economic Research Forum (ERF), Cairo, Egypt 


\section{Introduction}

Obesity is the second important health behavior after smoking that is widely examined in the health economics literature. Nevertheless, the number of studies on obesity is higher than the number of studies on smoking in the recent decades. This is because, prevalence of smoking has decreased over the years, while at the same time, obesity became an important health problem, not only in the USA, but also in other developed countries. The recent research suggests that obesity seriously threatens the individuals' lives. Following the increase in the obesity rates, and the simultaneous decrease in smoking rates in the USA in the past 30 years, Stewart et al. (2009) forecast the life expectancy and quality adjusted life expectancy for an 18 years old individual. They find that the benefits of the decline in smoking rates, unfortunately, cannot beat the negative impacts of the increased obesity rates. Their results are robust for multiple scenarios and different projections.

There are several studies that examine the determinants of obesity in the literature. The determinants of obesity generally considered are age, gender, education level, level of income and labor market statuses. Among all these factors, the association between education level and obesity is the most widely studied topic. There are many studies on this topic in the developed countries however the evidence from developing countries is less. In this paper we provide evidence from Turkey which is a developing country. Brunello et al. (2013), Webbink et al. (2010), Kemptner et al. (2011), Jürges et al. (2011) and Arendt (2005) all examine the causal effect of education on probability of being overweight/obese and/or individual's Body Mass Index (BMI) levels. In these studies, the impact of education is contradictory. For instance, Brunello et al. (2013) find evidence that the impact of years of schooling is negatively significant for females in all the countries they examine, however, it is insignificant for males in most of the countries ${ }^{1}$. In contrast, Webbink et al. (2010) find that having higher levels of education reduces the risk of obesity for males, however, for females, they do not find a significant relationship between education and obesity in Australia. Kemptner et al. (2011) find that an increase in the years of schooling decreases the likelihood of being obese for both men and women in West-Germany. However, Jürges et al. (2011) do not find a significant association between education and probability of being overweight and obese in WestGermany. Arendt (2005) provides evidence that years of education and normal ranges of BMI

\footnotetext{
${ }^{1}$ These countries are Austria, Denmark, Germany, Greece, Italy, Portugal, Spain, Sweden and United Kingdom.
} 
have a negative relationship in Denmark. Therefore, one can conclude that the causal effect of education on BMI levels is mixed across the countries.

There are a few studies that investigate the determinants of obesity in Turkey. Erem et al. (2004), Hatemi et al. (2003) and Yumuk (2005) are some of the studies that examine the factors which may affect obesity ${ }^{2}$. All of these studies concentrate on different regions of Turkey. For instance, Erem et al. conduct their study in Trabzon region, while Hatemi et al. investigate the determinants of obesity for just 11 cities in Turkey. Compared to previous two studies, Yumuk conducts his analysis on richer sample, as he concentrates on 59 randomly selected cities in different regions of Turkey. However he only proposes descriptive statistics about the determinants of obesity. Nevertheless, these studies draw attention to the increasing trend in obesity in Turkey. In fact, currently the Ministry of Health has started a campaign against obesity especially warning and providing information on the billboards in the hospitals.

To our knowledge, Tansel and Karaoglan (2014) is the first study that examine the determinants of health related behaviors in Turkey by using a rich micro data set, namely the Turkish Health Survey (THS) prepared by Turkish Statistical Institute (TURKSTAT). They examine the determinants of health behaviors, by concentrating on education. One of the health related outcomes they use is the individual's Body Mass Index (BMI). They find that individual's BMI decreases as his/her education level increases. In addition, they find females have significantly higher levels of BMI than males, urban residents have higher BMI levels than rural ones and BMI levels of widowed/divorced individuals are significantly lower from that of either married or single individuals. Next, both the employed and unemployed individuals have lower BMI levels than the ones who are out of labor force and they find a positive association between individual's BMI level and household income.

In a more recent study using Instrumental Variable (IV) methodology, Tansel and Karaoglan (2016) examine the causal effect of education on individual's BMI levels by using the same data set as this study. They take the education expansion of the early 1960s in Turkey, as an instrument for education and find that education causes and increase in BMI level. Likewise, Cesur et al. (2014) also find that men, who are between 18 and 30 years old with higher levels of education are more likely to be obese or overweight than the less educated in Turkey, by using the same data set and by implementing an IV technique.

\footnotetext{
${ }^{2}$ See Tansel and Karaoglan (2014) for the authors' findings.
} 
All of those studies perform their analysis by using Ordinary Least Squares (OLS) or the TwoStage Least Squares (2SLS) techniques. It is important to note that both the OLS and the 2SLS estimation processes give the effect of covariates upon the mean of the dependent variable or the BMI. This overlooks the fact that covariates are not homogeneous across the distribution of BMI and their effect may differ across the quantiles of BMI. Therefore, in this paper, we reinvestigate the determinants of BMI by using quantile regression $(\mathrm{QR})$ technique following Koenker and Basset (1978). This is expected to reveal a more robust relationship between education and BMI. By implementing the QR methodology, our objective is to see how education as well as other factors affect the individual's BMI at different quantiles of the distribution of BMI. This paper is the first paper that uses a $\mathrm{QR}$ approach to examine the determinants of obesity in Turkey, conducted with a large micro data set. It will be worthwhile to see the different impacts of various factors on individual's BMI at different quantiles of BMI for the policy purposes.

QR is a rather popular method in recent health economics literature. For instance, Costa-Font et al. (2009) examine the BMI gaps among females in Spain and Italy by using quantile regression technique. Garcia Villar and Quintana-Domeque (2009) investigate the association between household income (along with other factors) and BMI in nine European countries ${ }^{3}$ by using quantile regression method. In a different study Atella et al. (2008) examine the impact of BMI on wages across the different quantiles of the wage distribution for nine ${ }^{4}$ countries using European Community Household Panel data for the period 1998-2001.

Our results suggest that higher education levels has negative impact on individual's BMI levels and this negative impact considerably increases at higher quantiles of BMI. QR results provide mixed evidence for the gender effect: We observe at lower quantiles of BMI, the gender effect is positive, whereas at the higher quantiles the gender effect is negative stressing the fact that males are more obese than females at lower quantiles and females are more obese than males at higher quantiles. Age and BMI level has an inverted U-shape relationship across the quantiles which reaches a high level at the top quantiles. Therefore, one can conclude that obesity is higher at older ages. Obesity is significantly higher in the urban areas than in the rural areas at the lower quantiles but they do not significantly differ at the higher quantiles of BMI. Regarding the marital status, we find that single individuals are less obese or overweight than the widowed/divorced and this effect increases systematically across the quantiles of BMI. Inactive

\footnotetext{
${ }^{3}$ The countries they analyze are: Austria, Belgium, Denmark, Finland, Greece, Ireland, Italy, Portugal and Spain

${ }^{4}$ The countries they examine are the same in Villar and Quintina-Domeque (2009).
} 
individuals are more obese compared to employed or unemployed individuals and this effect is higher at the top quantiles. Finally, our results provide robust evidence that household income has a positive association with the individual's BMI at all quantiles of the BMI.

The rest of the paper is organized as follows: Section 2 introduces a brief literature review that focuses on the reasons of rising trend in obesity. Section 3 introduces the data and methodology. Section 4 presents the quantile regression results. Section 5 concludes.

\section{Possible Reasons of Obesity in the Literature}

The reasons behind the rising trend in obesity has been examined by several authors especially for the USA where prevalence of obesity is rather high with 36.5 per cent in $2014^{5}$. Chou et al. (2002) examine the possible reasons for rapidly increasing obesity rates for individuals above 25 in the USA by using 1984-1999 Behavioral Risk Factor Surveillance System data set. They attribute the increase in obesity rates to 3 major economic changes. First, as a result of the increase in the value of time, especially of women, female labor force participation rates and females' hours of work also increased. Therefore, females spend less time at home and on preparing home-made foods. This increases the demand for convenience foods. Second, since cigarette prices has increased as well as the anti-smoking campaigns intensified, many people gave up smoking. The reduction in smoking results with gaining body weight. Last, the number of fast food restaurants have increased over time. Because, the cost of eating in fast food restaurants are less than the cost of eating in another restaurants which provides healthy food and because that cost is also less than the cost of making food at home, people prefer to eat in fast food restaurants more often, which leads to huge caloric intake.

Later on, Cutler et al. (2003) also examine the possible reasons for rising obesity rates in the USA. The authors attribute the increase in obesity rates to technological improvement. They argue that technological enhancement led to an increase both in the variation and frequency of food consumption and it gives rise to switching to high-calorie/high-flavor prepared foods that were previously unavailable. With the improvement in technology, the tools that induce the prevalence of convenience foods, such as vacuum packing, improved preservatives, deep freezing, artificial flavors and microwaves become easily available then before, hence homemade cooking decreased as the food manufacturers are able to cook centrally and ship it to the

\footnotetext{
${ }^{5}$ Source: Center of Disease Control (CDC): https://www.cdc.gov/nchs/data/databriefs/db219.pdf
} 
households. This is easier than cooking at home especially for the spouses who are both employed. The authors conclude that increase in the consumption of mass food led to increase in obesity rates in both USA and most of the OECD countries, such as UK, Australia and Canada. They note that the obesity rates in Germany and France are relatively lower because these countries support the traditional food consumption rather than fast food consumption. They also indicate that caloric intake increases over time but caloric expenditure does not, which also gives rise to prevalence of obesity. Last, unlike Chou et al. (2002), the authors do not think that increase in labor force participation of women leads to the rise in the obesity rates.

Philipson and Posner (2003) also examine the reasons for huge growth in obesity by establishing a theoretical model which links to increase in prevalence of obesity to the technological improvement. Apart from the rise in calorie intake and reduction in exercise, the authors attribute the increasing trend in obesity rates to the fact that individuals can get addicted to eating after some time ${ }^{6}$.

Next, Rashad and Grossman (2004) also investigate the possible reasons for obesity. They cite several reasons. First, caloric intake increases due to more affordable prices. Second, microwavable meals and other foods that are easy to cook are desirable because they are quicker to prepare; they are also fattier and higher in caloric content. This is exactly what Cutler et al. (2003) suggest. Third, decline in physical activity and urban sprawl also leads to increase in obesity. Fourth, eating out at fast food restaurants and full service restaurants also raise the prevalence of obesity and they stress that this is due to the increase in female labor force participation as females prefer to eat out or prepare convenience food since they spend less time at home than before. This is also consistent with Chou et al. (2002)'s ideas. Finally, the authors refer smoking as a tool to control weight, therefore high taxes on smoking and anti-smoking campaigns lead to a decrease in smoking and consequently increase in obesity rates. The authors stress that there are several consequences of obesity such as hypertension, high cholesterol, coronary heart disease, type 2 diabetes, depression, and various types of cancer. In order to prevent the negative costs of obesity, the authors suggest some policies such as imposing food taxes, and rewarding exercise or subsidizing the exercise facilities and programs.

Phillipson and Posner (2008) state that obesity is not only a public health problem but also an economic problem. First, they argue that the increase in obesity rates cannot be just explained

\footnotetext{
${ }^{6}$ The authors do not make an applied analysis for a specific country, they examine the determinants of obesity by establishing a static, theoretical model.
} 
with biological factors and genes, obesity also depends on the choices of people. Second, they believe that obesity may create both social costs and private costs, and therefore the government may impose policies to reduce the obesity. Hence, the economists should propose cost reducing methods to policy makers. Different from Chou et al. (2002) and Cutler et al. (2003), Phillipson and Posner suggest that obesity is rising over time as a result of switching from agricultural economies to the industrial ones. They argue that when economies are based on agriculture, people exercise as a part of their job. However, after industrialization, exercise is not an element of the individual's job anymore. In addition, due to technological improvement, food becomes cheaper whereas exercise becomes more expensive. The authors also note that the wide use of computers and television give rise to the childhood obesity. Like Chou et al. (2002) and Cutler et al. (2003), Phillopson and Posner also argue that reduction in prices, lead to an increase in the consumption of fast food. The authors also consider the relationship between obesity, cigarette and alcohol consumption. They claim that lower relative prices of alcohol and higher relative prices of smoking lead to increase in obesity rates. Different from the previous studies, Phillopson and Posner discuss that the social aspects of obesity may play an important role in decreasing the obesity rates. They believe that if prevalence of obesity is rare in a society, the individuals consider obese ones as abnormal. This negative perception can help to keep obesity under control. However, if the prevalence of obesity is higher, the abnormal image of obesity disappears as it becomes more common, and this may cause an increase in obesity rates.

Next, Phillipson and Posner (2008) focus on the relationship between income and obesity. They maintain that in advanced countries people have more sedentary life-styles due to the type of jobs they have. This causes a rise in both income and weight of individuals living in those countries. The authors test the relationship between income and obesity by assuming health is a normal good, which provides non-monotonic association between income and weight. For the poor and underweight people, increase in income level leads to more food consumption and this results with a weight increase. However, for the rich and overweight people, the rise in income might lead to weight loss since these individuals have more opportunities to invest in facilities such as gymnasium, in order to reach their ideal weight. Therefore, increase in income leads to increase in weight among the poorest groups but, it leads to a decrease in weight throughout the upper half of the income distribution ${ }^{7}$.

\footnotetext{
${ }^{7}$ In this study, the authors make a critic of the book "Obesity, Business and Public Policy". They discuss the possible reasons of rising trend in obesity in general, but they mainly concentrated on the USA case.
} 


\section{Data and Methodology}

In this study, we use Turkish Health Survey Data Set (THS) for the years 2008, 2010 and 2012. THS is cross sectional data set over individuals. It is prepared and conducted by Turkish Statistical Institute (TURKSTAT). Regarding the descriptive statistics of covariates, we do not detect any significant differences between these three data sets. Therefore, we pool the data sets and conduct the empirical analysis ${ }^{8}$. In this survey health related questions are asked separately for 3 different age groups namely, 0-6, 7-14 and 15 or above. We concentrate on individuals above 25 in order to circumvent the problem of incomplete education, since in Turkey, individuals finish their schooling approximately at the age of 25 . The pooled data set contains 46,473 individuals above 25 years old.

In THS, demographic factors of the respondents above 25, such as age, gender, education level, marital status, household income, region (urban/rural) and labor market status (employed, unemployed or inactive), are available. Individual's self-reported age (in continuous terms) is available in the THS data set. We use this information directly in our empirical analysis. For gender, we define a dummy variable which is equal to 1 if the individual is male, 0 if the individual is female. We group the marital statuses of the respondents as married, single and widowed/divorced.

The variable "Years of Schooling" is constructed in the following manner: If the individual is illiterate, we assume that his/her years of schooling is equal to 0 . Next, if the individual is literate but not graduated from any school then his/her years of schooling is taken as 2 . The individual's years of schooling is assumed to be equal to 5, 8 and 11 if he/she has completed primary, middle and high schools respectively. Finally, the individual's years of schooling is equal to 15 if the individual is a college/university graduate or he/she has higher degree. We considered three employment statuses as employed, unemployed and inactive. The respondents who state that they have a regular job are referred to as "employed", whereas the individuals who state that they are not working but are looking for job are referred as "unemployed". The respondents who state that they are seasonal workers, students, housewives or pensioners, and the individuals who state that they are not able to work are considered as inactive. Next, in the THS the respondents are asked to tell or (if they do not know) guess their monthly net household income. The income categories are divided into 11 groups. These are: "Less than 350 Turkish Liras (TL), 351-500 TL, 501-620 TL, 621-750 TL, 751-900 TL, 901-1100 TL, 1101-1300 TL,

\footnotetext{
${ }^{8}$ Separate analysis of the 2008, 2010 and 2012 surveys are available from authors upon request.
} 
1301-1700 TL, 1701-2300 TL, More than 2301 TL, I do not want to answer this question". We take the mid-points of each group and determine the individual's household income accordingly. In the empirical analysis we use the logarithm of the household income as the control variables a proxy for the individual's income since the individual income is not available in the THS data sets.

The indicator for obesity/overweight is the individual's Body Mass Index (BMI) which can be found by dividing the self-reported weight (in kilograms) by the square of self-reported height (in meters). We report the observation as missing, if the individual does not report his/her height and/or weight. Therefore, we are left with 41,074 observations. The descriptive statistics for four different BMI groups (underweight/normal/overweight/obese) as well as the statistics for BMI is presented in Table 1.

\section{<Table 1 About Here>}

We observe in Table 1 that average years of schooling is lower among the obese individuals. Females seem to be more obese than males and males seem to be more overweight than females. The prevalence of obesity increases as the individual gets older. We do not find significant variation in the weight ranges of urban and rural residents. Married individuals seem to be more overweight, whereas widowed/divorced individuals seem to be more obese relative to the other marital status groups. Descriptive statistics also suggest that the occurrence of obesity is higher among inactive individuals and the household income is slightly higher among overweight individuals.

In this study, we conduct Quantile Regression (QR) analysis. By applying this methodology, we are able to examine how the covariates considered affect the BMI at different quantiles of the distribution of BMI. As a result, we are able to see an extensive view of the effects of the determinants of BMI. Apart from providing more general results, QR has other advantages over OLS. For instance, quantile regression is more robust to outliers than OLS. In addition, unlike OLS, we do not need to make strong stochastic assumptions in quantile regressions (See Cameron and Trivedi, 2005, p. 85). In order to have more efficient and consistent estimates we used bootstrapped techniques ${ }^{9}$ in the computation of standard errors as suggested by Koenker and Hallock (2001).

Based on the previous literature, we establish our model as follows:

\footnotetext{
${ }^{9}$ We replicated the bootstrapped quantile regressions 400 times and get the robust results
} 


$$
Q_{B M I, \tau}=\beta_{0}+\beta_{1}(\tau) E_{i}+X^{\prime}{ }_{i} \beta_{2}(\tau)+\varepsilon_{i}
$$

In equation (1), $\tau$ corresponds to the $\tau^{\text {th }}$ quantile of BMI distribution. Hence, $Q_{B M I, \tau}$ refers to the individual's BMI in the $\tau^{\text {th }}$ quantile. The variable $\mathrm{E}_{\mathrm{i}}$ shows the individual's completed years of schooling, therefore the coefficient $\beta_{1}(\tau)$ shows the impact of education level on individual's $\mathrm{BMI}$ at the $\tau^{\text {th }}$ quantile. The vector $\mathrm{X}$ includes other controls such as gender, age, region, marital status, labor market status, household income and year dummies, therefore $\beta_{2}(\tau)$ shows the effect of these covariates on the individual's BMI on the $\tau^{\text {th }}$ quantile. Finally, $\varepsilon_{i}$ refers to the unobserved factors, such as genetics.

\section{Results}

Table 2 presents both the OLS estimation and the QR estimation results. The QR is estimated for the $5^{\text {th }}, 10 \mathrm{th}, 25 \mathrm{th}, 50^{\text {th }}, 75 \mathrm{th}, 90^{\text {th }}$, and $95^{\text {th }}$ quantiles of the BMI distribution. One should be careful in the interpretation of our estimated coefficients in the sense that they do not provide a causal relationship, rather they show the controlled associations between the each control variable and individual's BMI at different quantiles of BMI.

\section{<Table 2 About Here>}

Table 2 shows that the effect of individual's years of schooling is insignificant at the $5^{\text {th }}$ and $10^{\text {th }}$ quantiles. But, starting from the $25^{\text {th }}$ quantile we see the negative impact of the years of schooling on the BMI. This effect rises systematically from the $25^{\text {th }}$ to the $90^{\text {th }}$ quantile. It decreases slightly at the $95^{\text {th }}$ quantile (from 0.22 to 0.19 ). The result is consistent with the findings of Costa-Font et al. (2009), who also examine the association between individual's BMI level and education using QR analysis for Italy and Spain. Similar to our study Costa-Font et al. also find that the negative impact of education on BMI is highest in absolute value at highest quantiles of BMI for both countries.

The effect of the logarithm of household income is positive and significant on the BMI levels in all quantiles, In general, our results suggest that people with higher income levels have higher BMI levels. In fact, this is an expected result since people can spend more on various healthy or unhealthy food if their income is high. In contrast, Villar and Quintana-Domeque (2009) find mixed evidence regarding this issue for various European Union countries ${ }^{10}$. Their results do

\footnotetext{
${ }^{10}$ The countries they study are Austria, Belgium, Denmark, Finland, Greece, Ireland, Italy, Portugal and Spain.
} 
not suggest a significant relationship between household income and BMI for men, but, they find a negative relationship for women. They state that the difference between men and women mainly comes from the own-labor earnings for women.

The gender effect on BMI is mixed across the quantiles. At lower quantiles of BMI, males have higher BMI levels. However, at the highest quantiles of BMI $\left(75^{\text {th }}, 90^{\text {th }}\right.$ and $95^{\text {th }}$ quantile) females have higher BMI levels. The gender effect increases in absolute values across the quantiles. This result indicates that prevalence of obesity and overweight is higher among the females in Turkey.

The relationship between age and BMI level is concave as it is the case in the OLS results. The impact of age on BMI 1 increases monotonically across the quantiles. This implies that the occurrence of overweight and obesity raises with age. This finding is consistent with CostaFont et al. (2009) and Villar and Quintana-Domeque (2009) in the European countries.

People who live in urban areas have significantly higher BMI levels than people who live in rural areas. The marginal effect of region variable increases up to the $90^{\text {th }}$ quantile. In the top two quantiles the effect of region on individual's BMI becomes insignificant indicating that at the top quantiles obesity does not differ between the urban and rural areas. The life style is more sedentary in urban areas and unhealthy food consumption is observed more often in urban areas. These can lead to increase in obesity rates in urban areas. However, we should note that the consumption of foods with high calories such as white bread, biscuits, butter, sugar, honey and molasses is higher in rural areas ${ }^{11}$. Therefore, it is not surprising that the prevalence of obesity does not significantly differ between two regions at the top quantiles of BMI.

Regarding the marital status the results suggest that single people have significantly lower BMI levels relative to the widowed/divorced individuals. The effect of being single increases systematically in absolute value with the level of BMI, rising from 0.86 in $5^{\text {th }}$ quantile to 1.56 in $95^{\text {th }}$ quantile. Being married has no significant effect on BMI level in lower quantiles. However, starting from the $50^{\text {th }}$ quantile married people have significantly lower BMI levels than widowed/divorced individuals. The effect of being married on BMI level raises monotonically from the $50^{\text {th }}$ to the $95^{\text {th }}$ quantile. However, the impact of being married is not as strong as that of being single on individual's BMI levels. Costa-Font et al. (2009) find similar results for Spain and Italy.

\footnotetext{
${ }^{11}$ Source: Turkish Nutrition and Health Survey 2010.
} 
Being unemployed does not significantly affect the BMI level in the $5^{\text {th }}$ quantile. At the $10^{\text {th }}$ quantile, being unemployed leads to 31 per cent decrease in the BMI level. The impact of being unemployed raises monotonically from the $10^{\text {th }}$ quantile and it reaches its highest value $(1.34$ in absolute value) in the $90^{\text {th }}$ quantile. The impact of being employed also increases systematically starting from the $5^{\text {th }}$ quantile and the negative effect of being employed on BMI level is highest at the $90^{\text {th }}$ quantile (54 per cent). In short, our findings imply that both the employed and the unemployed people have significantly lower BMI levels than the inactive people. These results are consistent with those of Costa-Font et al. (2009) in Italy and Spain.

Finally, we find both year dummies are positive and significant across all quantiles. The impacts of both the 2010 dummy and the 2012 dummy increase monotonically from the lower to upper quantiles. Further, there has been a larger increase in the BMI in all of the quantiles in 2012 than in 2010, except in the $90^{\text {th }}$ quantile. This result indicates that in Turkey, the prevalence of obesity have been increasing over time.

\section{Conclusion}

In this paper, first, we investigate the determinants of BMI by using QR technique in order to see how education as well as other factors affect the individual's BMI level at different quantiles of the distribution of BMI. QR results suggest individual's BMI decreases with additional years of schooling. The negative effect of education increases monotonically from the $25^{\text {th }}$ to the $90^{\text {th }}$ quantile and rather still high at the top quantile of the BMI. Therefore, we can conclude that people with higher levels of education are more aware of the dangers of obesity.

Quantile regression results also suggest that females tend to be more obese than males as gender effect is found to be negative at the highest quantiles of the BMI. We also find that age and BMI have an inverted U-shape relationship implying that individuals are more likely to be overweight or obese as they age. Next, our results provide robust evidence that prevalence of obesity does not significantly differ between urban areas and rural areas, since the region effect is found to be insignificant at the top two quantiles of BMI. The single individuals have significantly lower BMI levels relative to widowed/divorced. The negative effect of being single increases systematically in absolute value across the quantiles of BMI. The effect for the married is also negative but smaller than those for the single. The inactive individuals have significantly higher BMI levels compared to the employed and unemployed individuals and the 
negative impact of being in labor force gradually increases in absolute value across the quantiles of BMI. Our results provide robust evidence that individual's BMI level and household income are positively associated with each other, as the positive association between them, although decline, remain to be valid across the quantiles of BMI. Last, our findings indicate that the prevalence of obesity has increased over time in Turkey, as the positive impact of year dummies for 2010 and 2012 raises across the quantiles of the BMI. Hence, QR results reveal that obesity is becoming a serious health problem in Turkey over time like in the developed countries.

To prevent the severe health consequences of obesity in Turkey the possible policy suggestions can be as follows: First, health lectures in high schools should be implemented examining the consequences of obesity. In schools, children should be informed about healthy nutrition processes. The consumption of the foods with high calorie such as fast-food is widespread among children. Both the schools and families should be notified about the unhealthy fast food choices. The government can increase the public health expenditures by providing seminars to adults on the dangers of being obese. From QR results, we observe that individuals are faced with obesity problem in rural areas as well. Especially, physicians and teachers in rural areas should inform the public about the risks of consuming fat, sugar, salt and flour in large amounts. People who live in rural areas may tend to gain weight due to consuming such foods in large amounts. Therefore, providing seminars and campaigns on the risks of obesity in both urban and rural areas are necessary. It may take a long time for education related policies to succeed in a developing country, but at least children may grow up to be informed of the health consequences of obesity with effective teaching.

Apart from educating the public several other measures can be considered. There are many fastfood restaurants with different brands, especially in urban areas. Quotas can be put on the number and operation of fast-food restaurants. For instance, every brand may have just one restaurant in a certain region. Fast-food restaurants are cheaper and preferred especially by students. Government can tax fast-food consumption at a higher rate. Convenience foods which are sold in super markets are also easy to make and cheap. However, they also provide high calories to the body. The tax on these foods should also be increased.

Tansel and Karaoglan (2014) show that education has positive impacts on fruits and vegetables consumption and exercising. Observance of these health behaviors are important in order to maintain normal ranges of BMI. Fruit and vegetable consumption should also be promoted in schools in the early years of education. Government can increase its spending on the advertisements related to the importance of these two health behaviors. Especially in high 
inflationary periods or due to seasonal factors various fruits and vegetables are very expensive. It is better to put price ceiling at least in certain foods so that the individuals can afford consuming them. The sports centers are generally expensive and operated by the private sector in Turkey. Therefore, not everyone can have a chance to exercise regularly. The sports facilities in schools should be increased, and they should be free or very cheap for the young. For the old, the government can establish special social sports centers so that they can cheaply exercise.

\section{References}

Arendt, J. N. (2005) "Does Education Cause Better Health? A Panel Data Analysis Using School Reforms for Identification." Economics of Education Review 24(2): 149-160.

Atella, V., N. Pace, and D. Vuri (2008) "Are Employers Discriminating with respect to Weight?: European Evidence Using Quantile Regression." Economics and Human Biology 6 (3): 305-329.

Brunello, G., D. Fabbri, and M. Fort (2013) "The Causal Effect of Education on Body Mass: Evidence from Europe," Journal of Labor Economics 31(1): 195-223.

Cameron, C.A., and P.K. Trivedi.(2005) Microeconometrics: Methods and Applications. Cambridge University Press. New York.

Center of Disease Control (CDC): https://www.cdc.gov/nchs/data/databriefs/db219.pdf (Accessed on December 2016).

Cesur, R., B. Dursun, and N. Mocan (2014) "The Impact of Education on Health and Health Behavior in a Middle-Income, Low-Education Country”. National Bureau of Economic Research (NBER) Working Paper No. 20764. Cambridge, MA.

Chou, S. Y., M. Grossman, and H. Saffer (2002) "An Economic Analysis of Adult Obesity: Results from the Behavioral Risk Factor Surveillance System." Journal of Health Economics 23 (3): $565-587$.

Costa-Font, J., D. Fabbri, and J. Gil (2009) "Decomposing Body Mass Index Gaps between Mediterranean Countries: A Counterfactual Quantile Regression Analysis." Economics and Human Biology 7 (3): 351-365. 
Cutler, D. M., E.L. Glaeser, and J.M. Shapiro (2003) "Why Have Americans Become More Obese?," The Journal of Economic Perspectives 17 (3): 93-118.

Erem, C., et al. (2004) "Prevalence of Obesity and Associated Risk Factors in a Turkish Population (Trabzon City, Turkey)," Obesity Research 12 (7): 1117-1127.

Hatemi, H., et al. (2003) "Prevalence of Overweight and Obesity in Turkey," Metabolic Syndrome and Related Disorders 1(4): 285-290.

Jürges, H., S. Reinhold and M. Salm (2011) "Does Schooling Affect Health Behavior? Evidence from Educational Expansion in Western Germany" Economics of Education Review 30: $862-872$.

Kemptner,D., H. Jürges and S. Reinhold (2011) "Changes in Compulsory Schooling and the Causal Effect of Education on Health: Evidence from Germany", Journal of Health Economics 30 (2): 340-354.

Koenker, R., and G. Bassett (1978) "Regression Quantiles" Econometrica: Journal of the Econometric Society 46 (1): 33-50.

Koenker, R., and K. Hallock (2001) "Quantile Regression: An Introduction," Journal of Economic Perspectives 15 (4): 43-56.

Philipson, T. J., and R. A. Posner (2003) "The Long-Run Growth in Obesity as a Function of Technological Change." Perspectives in Biology and Medicine 46 (3): 87-107.

Philipson, T. J., and R. A. Posner (2008) "Is the Obesity Epidemic a Public Health Problem? A Review of Zoltan J. Acs and Alan Lyles's" Obesity, Business and Public Policy." Journal of Economic Literature 46 (4): 974-982.

Rashad, I. and M. Grossman (2004) "The Economics of Obesity." Public Interest 156: 104-113.

Stewart, S. T., D. M. Cutler, and A. B. Rosen (2009) "Forecasting the Effects of Obesity and Smoking on US Life Expectancy." New England Journal of Medicine 361 (23): 2252-2260.

Tansel, A., and D. Karaoğlan, (2014) "Health Behaviors and Education in Turkey." Bonn, Germany: Institute for the Study of Labor (IZA) Discussion Paper No: 8262.

Tansel, A., and D. Karaoğlan, (2016) "The Causal Effect of Education on Health Behaviors: Evidence from Turkey" Ankara, Turkey: Economic Research Center (ERC) Working Paper No: $16 / 06$. 
Turkish Nutrition and Health Survey 2010

(http://www.sagem.gov.tr/TBSA_Beslenme_Yayini.pdf) (Accessed on April 2015)

Villar, J. G., and C. Quintana-Domeque (2009) "Income and Body Mass Index in Europe." Economics and Human Biology 7 (1): 73-83.

Webbink, D., N. G. Martin and P. M. Visscher (2010) "Does Education Reduce the Probability of Being Overweight?” Journal of Health Economics 29 (1): 29-38.

Yumuk, V. D. (2005) "Prevalence of Obesity in Turkey." Obesity Reviews 6 (1): 9-10. 
Table 1. Descriptive Statistics for BMI

\begin{tabular}{|c|c|c|c|c|c|}
\hline Variable & $\begin{array}{l}\text { Underweight } \\
\text { (BMI<18.5) }\end{array}$ & $\begin{array}{l}\text { Normal Weight } \\
(18.5<=B M I<=24.99)\end{array}$ & $\begin{array}{l}\text { Overweight } \\
(25<=B M I<30)\end{array}$ & $\begin{array}{l}\text { Obese } \\
(\text { BMI>=30) }\end{array}$ & Total \\
\hline Male* & $\begin{array}{l}0.01 \\
(0.10)\end{array}$ & $\begin{array}{l}0.37 \\
(0.48)\end{array}$ & $\begin{array}{l}0.45 \\
(0.50)\end{array}$ & $\begin{array}{l}0.17 \\
(0.38)\end{array}$ & 1.00 \\
\hline Female* & $\begin{array}{l}0.02 \\
(0.15)\end{array}$ & $\begin{array}{l}0.38 \\
(0.48)\end{array}$ & $\begin{array}{l}0.34 \\
(0.47)\end{array}$ & $\begin{array}{l}0.26 \\
(0.44)\end{array}$ & 1.00 \\
\hline Age (Years) & $\begin{array}{l}42.57 \\
(16.79)\end{array}$ & $\begin{array}{l}43.77 \\
(14.96)\end{array}$ & $\begin{array}{l}47.47 \\
(13.94)\end{array}$ & $\begin{array}{l}50.51 \\
(13.08)\end{array}$ & $\begin{array}{l}46.65 \\
(14.44)\end{array}$ \\
\hline Age-Squared & $\begin{array}{l}2093 \\
(1759)\end{array}$ & $\begin{array}{l}2139 \\
(1534)\end{array}$ & $\begin{array}{l}2447 \\
(1443)\end{array}$ & $\begin{array}{l}2722 \\
(1385)\end{array}$ & $\begin{array}{l}2385 \\
(1489)\end{array}$ \\
\hline Urban* & $\begin{array}{l}0.02 \\
(0.13)\end{array}$ & $\begin{array}{l}0.37 \\
(0.48)\end{array}$ & $\begin{array}{l}0.39 \\
(0.49)\end{array}$ & $\begin{array}{l}0.22 \\
(0.41)\end{array}$ & 1.00 \\
\hline Rural* & $\begin{array}{l}0.02 \\
(0.14)\end{array}$ & $\begin{array}{l}0.37 \\
(0.48) \\
\end{array}$ & $\begin{array}{l}0.39 \\
(0.48)\end{array}$ & $\begin{array}{l}0.22 \\
(0.41)\end{array}$ & 1.00 \\
\hline \multicolumn{6}{|c|}{ Marital Status } \\
\hline Married* & $\begin{array}{l}0.01 \\
(0.12)\end{array}$ & $\begin{array}{l}0.35 \\
(0.48) \\
\end{array}$ & $\begin{array}{l}0.41 \\
(0.49)\end{array}$ & $\begin{array}{l}0.23 \\
(0.42)\end{array}$ & 1.00 \\
\hline Single* & $\begin{array}{l}0.05 \\
(0.23)\end{array}$ & $\begin{array}{l}0.62 \\
(0.49)\end{array}$ & $\begin{array}{l}0.25 \\
(0.44)\end{array}$ & $\begin{array}{l}0.08 \\
(0.26)\end{array}$ & 1.00 \\
\hline Widowed/Divorced* & $\begin{array}{l}0.02 \\
(0.14)\end{array}$ & $\begin{array}{l}0.35 \\
(0.48)\end{array}$ & $\begin{array}{l}0.35 \\
(0.48)\end{array}$ & $\begin{array}{l}0.28 \\
(0.45)\end{array}$ & 1.00 \\
\hline \multicolumn{6}{|c|}{ Education } \\
\hline Years of Schooling & $\begin{array}{l}7.73 \\
(4.82)\end{array}$ & $\begin{array}{l}7.56 \\
(4.54) \\
\end{array}$ & $\begin{array}{l}6.99 \\
(4.30)\end{array}$ & $\begin{array}{l}5.81 \\
(4.02)\end{array}$ & $\begin{array}{l}6.96 \\
(4.39)\end{array}$ \\
\hline $\begin{array}{l}\text { Years of Schooling- } \\
\text { Squared }\end{array}$ & $\begin{array}{l}82.87 \\
(80.44)\end{array}$ & $\begin{array}{l}77.77 \\
(76.78)\end{array}$ & $\begin{array}{l}67.39 \\
(71.75)\end{array}$ & $\begin{array}{l}49.98 \\
(61.99)\end{array}$ & $\begin{array}{l}67.78 \\
(72.65)\end{array}$ \\
\hline \multicolumn{6}{|c|}{ Labor Market Status } \\
\hline Employed* & $\begin{array}{l}0.02 \\
(0.13)\end{array}$ & $\begin{array}{l}0.41 \\
(0.49)\end{array}$ & $\begin{array}{l}0.41 \\
(0.49)\end{array}$ & $\begin{array}{l}0.16 \\
(0.37)\end{array}$ & 1.00 \\
\hline Unemployed* & $\begin{array}{l}0.03 \\
(0.17)\end{array}$ & $\begin{array}{l}0.53 \\
(0.50)\end{array}$ & $\begin{array}{l}0.35 \\
(0.48)\end{array}$ & $\begin{array}{l}0.09 \\
(0.28)\end{array}$ & 1.00 \\
\hline Out of Labor Force* & $\begin{array}{l}0.02 \\
(0.14)\end{array}$ & $\begin{array}{l}0.34 \\
(0.47)\end{array}$ & $\begin{array}{l}0.38 \\
(0.48)\end{array}$ & $\begin{array}{l}0.26 \\
(0.44)\end{array}$ & 1.00 \\
\hline $\begin{array}{l}\text { Log Household Income } \\
\text { (TL) }\end{array}$ & $\begin{array}{l}6.88 \\
(0.64)\end{array}$ & $\begin{array}{l}6.95 \\
(0.63)\end{array}$ & $\begin{array}{l}6.98 \\
(0.59)\end{array}$ & $\begin{array}{l}6.95 \\
(0.59)\end{array}$ & $\begin{array}{l}6.96 \\
(0.61)\end{array}$ \\
\hline No. of Obs. in 2008 & 209 & 3998 & 3764 & 1943 & 9914 \\
\hline No. of Obs. in 2010 & 201 & 3844 & 3928 & 2317 & 10290 \\
\hline No. of Obs. in 2012 & 322 & 7570 & 8331 & 4647 & 20870 \\
\hline Total No. Of Obs. & 732 & 15412 & 16023 & 8907 & 41074 \\
\hline
\end{tabular}

Source: Authors' computations using 2008, 2010 and 2012 Turkish Health Survey

Notes : (1)*indicates a dummy variable

(2) The numbers in the paranthesis are standard deviations 
Table 2. OLS and Quantile Regression Results (Dependent Variable: Individual's BMI)

\begin{tabular}{|c|c|c|c|c|c|c|c|c|}
\hline Variable & OLS & Q5 & Q10 & Q25 & Q50 & Q75 & Q90 & Q95 \\
\hline \multicolumn{9}{|c|}{ Education } \\
\hline Years of Schooling & $\begin{array}{l}-0.10 * * * \\
(0.02)\end{array}$ & $\begin{array}{l}-0.03 \\
(0.03)\end{array}$ & $\begin{array}{l}-0.003 \\
(0.03)\end{array}$ & $\begin{array}{l}-0.05^{* *} \\
(0.03)\end{array}$ & $\begin{array}{l}-0.13 * * * \\
(0.03)\end{array}$ & $\begin{array}{l}-0.14 * * * \\
(0.03)\end{array}$ & $\begin{array}{l}-0.22 * * * \\
(0.04)\end{array}$ & $\begin{array}{l}-0.19 * * * \\
(0.06)\end{array}$ \\
\hline $\begin{array}{l}\text { Years of } \\
\text { Schooling- } \\
\text { Squared }\end{array}$ & $\begin{array}{l}-0.002 \\
(0.001)\end{array}$ & $\begin{array}{l}-0.002 \\
(0.001)\end{array}$ & $\begin{array}{l}-0.004 * * \\
(0.001)\end{array}$ & $\begin{array}{l}-0.002 \\
(0.002)\end{array}$ & $\begin{array}{l}0.0004 \\
(0.001)\end{array}$ & $\begin{array}{l}-0.0004 \\
(0.001)\end{array}$ & $\begin{array}{l}0.003 \\
(0.002)\end{array}$ & $\begin{array}{l}0.0004 \\
(0.003)\end{array}$ \\
\hline \multicolumn{9}{|c|}{ Demographic Factors } \\
\hline Male & $\begin{array}{l}-0.10^{*} \\
(0.05)\end{array}$ & $\begin{array}{l}0.79 * * * \\
(0.07)\end{array}$ & $\begin{array}{l}0.83 * * * \\
(0.07)\end{array}$ & $\begin{array}{l}0.76^{* * * *} \\
(0.06)\end{array}$ & $\begin{array}{l}0.38 * * * \\
(0.06)\end{array}$ & $\begin{array}{l}-0.34 * * * \\
(0.09)\end{array}$ & $\begin{array}{l}-1.27 * * * \\
(0.12)\end{array}$ & $\begin{array}{l}-1.71 * * * \\
(0.19)\end{array}$ \\
\hline $\operatorname{Age}\left(\mathbf{x 1 0}^{-1}\right)$ & $\begin{array}{l}4.54 * * * \\
(0.10)\end{array}$ & $\begin{array}{l}2.93 * * * \\
(0.15)\end{array}$ & $\begin{array}{l}3.21 * * * \\
(0.15)\end{array}$ & $\begin{array}{l}3.88 * * * \\
(0.11)\end{array}$ & $\begin{array}{l}4.42 * * * \\
(0.11)\end{array}$ & $\begin{array}{l}4.88 * * * \\
(0.15)\end{array}$ & $\begin{array}{l}5.34 * * * \\
(0.21)\end{array}$ & $\begin{array}{l}5.41 * * * \\
(0.32)\end{array}$ \\
\hline Age Square $\left(\times 10^{-3}\right)$ & $\begin{array}{l}-4.11 * * * \\
(0.10)\end{array}$ & $\begin{array}{l}-2.76^{* * *} \\
(0.15)\end{array}$ & $\begin{array}{l}-2.94 * * * \\
(0.16)\end{array}$ & $\begin{array}{l}-3.56 * * * \\
(0.11)\end{array}$ & $\begin{array}{l}-4.01 * * * \\
(0.11)\end{array}$ & $\begin{array}{l}-4.39 * * * \\
(0.15)\end{array}$ & $\begin{array}{l}-4.81 * * * \\
(0.20)\end{array}$ & $\begin{array}{l}-4.84 * * * \\
(0.32)\end{array}$ \\
\hline Urban & $\begin{array}{l}0.30 * * * \\
(0.05)\end{array}$ & $\begin{array}{l}0.25 * * * \\
(0.08)\end{array}$ & $\begin{array}{l}0.30 * * * \\
(0.07)\end{array}$ & $\begin{array}{l}0.28 * * * \\
(0.06)\end{array}$ & $\begin{array}{l}0.26 * * * \\
(0.06)\end{array}$ & $\begin{array}{l}0.27 * * * \\
(0.07)\end{array}$ & $\begin{array}{l}0.16 \\
(0.10)\end{array}$ & $\begin{array}{l}0.25 \\
(0.16)\end{array}$ \\
\hline \multicolumn{9}{|c|}{ Marital Status } \\
\hline Married & $\begin{array}{l}-0.30 * * * \\
(0.10)\end{array}$ & $\begin{array}{l}0.06 \\
(0.13)\end{array}$ & $\begin{array}{l}0.12 \\
(0.11)\end{array}$ & $\begin{array}{l}-0.13 \\
(0.10)\end{array}$ & $\begin{array}{l}-0.19 * \\
(0.11)\end{array}$ & $\begin{array}{l}-0.59 * * * \\
(0.15)\end{array}$ & $\begin{array}{l}-0.59 * * * \\
(0.23)\end{array}$ & $\begin{array}{l}-0.98 * * * \\
(0.28)\end{array}$ \\
\hline Single & $\begin{array}{l}-1.37 * * * \\
(0.12)\end{array}$ & $\begin{array}{l}-0.86^{* * * *} \\
(0.18)\end{array}$ & $\begin{array}{l}-0.94 * * * \\
(0.15)\end{array}$ & $\begin{array}{l}-1.24 * * * \\
(0.13)\end{array}$ & $\begin{array}{l}-1.34 * * * \\
(0.14)\end{array}$ & $\begin{array}{l}-1.73 * * * \\
(0.19)\end{array}$ & $\begin{array}{l}-1.50 * * * \\
(0.29)\end{array}$ & $\begin{array}{l}-1.56^{* * * *} \\
(0.38)\end{array}$ \\
\hline \multicolumn{9}{|c|}{ Labor Force Status } \\
\hline Employed & $\begin{array}{l}-0.44 * * * \\
(0.06)\end{array}$ & $\begin{array}{l}-0.20 * * * \\
(0.08)\end{array}$ & $\begin{array}{l}-0.25^{* * * *} \\
(0.08)\end{array}$ & $\begin{array}{l}-0.44 * * * \\
(0.06)\end{array}$ & $\begin{array}{l}-0.43 * * * \\
(0.07)\end{array}$ & $\begin{array}{l}-0.54 * * * \\
(0.10)\end{array}$ & $\begin{array}{l}-0.55^{* * * *} \\
(0.14)\end{array}$ & $\begin{array}{l}-0.54 * * * \\
(0.19)\end{array}$ \\
\hline Unemployed & $\begin{array}{l}-0.92 * * * \\
(0.12)\end{array}$ & $\begin{array}{l}-0.26 \\
(0.21)\end{array}$ & $\begin{array}{l}-0.31 * * \\
(0.14)\end{array}$ & $\begin{array}{l}-0.69 * * * \\
(0.17)\end{array}$ & $\begin{array}{l}-0.86 * * * \\
(0.12)\end{array}$ & $\begin{array}{l}-1.29 * * * \\
(0.20)\end{array}$ & $\begin{array}{l}-1.34 * * * \\
(0.27)\end{array}$ & $\begin{array}{l}-1.23 * * * \\
(0.38)\end{array}$ \\
\hline $\begin{array}{l}\text { Log Household } \\
\text { Income }\end{array}$ & $\begin{array}{l}0.42 * * * \\
(0.05)\end{array}$ & $\begin{array}{l}0.50 * * * \\
(0.07)\end{array}$ & $\begin{array}{l}0.50 * * * \\
(0.06)\end{array}$ & $\begin{array}{l}0.49 * * * \\
(0.05)\end{array}$ & $\begin{array}{l}0.47 * * * \\
(0.06)\end{array}$ & $\begin{array}{l}0.35 * * * \\
(0.07)\end{array}$ & $\begin{array}{l}0.25 * * \\
(0.11)\end{array}$ & $\begin{array}{l}0.20 * \\
(0.12)\end{array}$ \\
\hline Dummy 2010 & $\begin{array}{l}0.26 * * * \\
(0.06)\end{array}$ & $\begin{array}{l}0.10 \\
(0.10)\end{array}$ & $\begin{array}{l}0.13^{*} \\
(0.08)\end{array}$ & $\begin{array}{l}0.16^{* *} \\
(0.07)\end{array}$ & $\begin{array}{l}0.17 * * * \\
(0.08)\end{array}$ & $\begin{array}{l}0.32 * * * \\
(0.10)\end{array}$ & $\begin{array}{l}0.37 * * * \\
(0.12)\end{array}$ & $\begin{array}{l}0.43^{* * *} \\
(0.16)\end{array}$ \\
\hline Dummy 2012 & $\begin{array}{l}0.29 * * * \\
(0.06)\end{array}$ & $\begin{array}{l}0.14 \\
(0.09)\end{array}$ & $\begin{array}{l}0.18 * * * \\
(0.07)\end{array}$ & $\begin{array}{l}0.24 * * * \\
(0.06)\end{array}$ & $\begin{array}{l}0.24 * * * \\
(0.07)\end{array}$ & $\begin{array}{l}0.28 * * * \\
(0.09)\end{array}$ & $\begin{array}{l}0.34 * * * \\
(0.12)\end{array}$ & $\begin{array}{l}0.48 * * * \\
(0.16)\end{array}$ \\
\hline (Pseudo) $\mathbf{R}^{2}$ & 0.11 & 0.05 & 0.06 & 0.06 & 0.06 & 0.06 & 0.08 & 0.08 \\
\hline $\mathbf{N}$ & 40699 & 40699 & 40699 & 40699 & 40699 & 40699 & 40699 & 40699 \\
\hline
\end{tabular}

Source: Authors' computations using 2008, 2010 and 2012 Turkish Health Survey

*** indicates $1 \%$ level of significance, **indicates $5 \%$ level of significance, *indicates $1 \%$ level of significance 